\title{
EXPERIMENTAÇÃO EM EAD PARA PRIVADOS DE LIBERDADE NO INSTITUTO FEDERAL DE EDUCAÇÃO CIÊNCIA E TECNOLOGIA DO RIO GRANDE DO NORTE (IFRN)
}

\author{
NATAL/RN JUNHO/2018 \\ Edneide da Conceição Bezerra ～- IFRN - edneide.bezerra@ifrn.edu.br \\ Tipo: Relato de Experiência Inovadora (EI) \\ Categoria: Estratégias e Políticas \\ Setor Educacional: EDUCAÇÃO SUPERIOR
}

\begin{abstract}
RESUMO
$O$ relato de experiência aborda a experimentação em EaD para privados de liberdade. Tem por objetivo contar o processo de inclusão desse público no ensino superior, utilizando como caminho a Educação a Distância. A experiência está sendo desenvolvida no Instituto Federal de Educação Ciência e Tecnologia do Rio Grande do Norte (IFRN), na modalidade EaD, no Curso Superior de Gestão Ambiental e se encontra ainda em fase inicial. Neste relato, contamos como se deu esse processo. Para isso, utilizamos como referência metodológica entrevistas com os profissionais envolvidos no processo de ensino no IFRN bem como os mediadores do Presídio Federal de Segurança Máxima de Mossoró. Desse modo, classificamos como metodologia a pesquisa exploratória. A experiência ainda tem um caráter experimental, posto que o processo/metodologia de atendimento ainda está em construção. Entendemos que o relato de experiência tem um importante papel de apresentar a ação que começou a ser desenvolvida no período letivo de 2017.2 na Instituição, bem como, contribuir para pesquisas que têm como facetas a EAD e a Educação Prisional.
\end{abstract}

Palavras-chave: PALAVRAS-CHAVE: Educação para privados de liberdade; Experimentação em EAD; Inclusão. 


\section{INTRODUÇÃO}

Dados do Levantamento Nacional de Informações Penitenciárias (Infopen) divulgados no fim do ano passado pelo Departamento Penitenciário Nacional (Depen), do Ministério da Justiça, apontam que o Brasil já é o terceiro país em número de presos, atrás apenas dos Estados Unidos e da China. O quarto colocado é a Rússia.

O total de pessoas encarceradas no país chegou a 726.712 em junho de 2016. Em dezembro de 2014, era de 622.202. Houve um crescimento de mais de 104 mil pessoas. Cerca de $40 \%$ são presos provisórios, ou seja, ainda não possuem condenação judicial. Mais da metade dessa população é de jovens de 18 a 29 anos e 64\% são negros.

A taxa de presos para cada 100 mil habitantes subiu para 352,6 indivíduos em junho de 2016. Em 2014, era de 306,22 pessoas presas para cada 100 mil habitantes.

Os crimes relacionados ao tráfico de drogas são os que mais levam pessoas às prisões, com $28 \%$ da população carcerária total. Somados, roubos e furtos chegam a $37 \%$. Homicídios representam $11 \%$ dos crimes que causaram a prisão. Do universo total de presos no Brasil, 55\% têm entre 18 e 29 anos.

Quanto à escolaridade, $75 \%$ da população prisional brasileira não chegaram ao ensino médio. Menos de $1 \%$ dos presos tem graduação. BOIAGO (2013, p.32) recorrendo ao documento da UNESCO (1995) reflete:

Pode-se constatar que a população carcerária é composta pelo segmento social marginalizado historicamente, o qual não teve, em sua condição de vida antes do encarceramento, acesso aos direitos sociais básicos, como saúde, trabalho e, em especial, educação. Em muitos casos, após o encarceramento muitos desses direitos continuam sendo negados aos reclusos (UNESCO, 1995).

Assim questionamos: como assegurar a afirmação de um direito humano, tão elementar como o acesso à educação formal aos privados de liberdade? A educação ainda se apresenta como grande instrumento para construção da cidadania.

No ambiente prisional, com todo o seu real e imaginário mundo, marcado historicamente pela inexistência de ações institucionalizadas, o processo educativo encontra desafios ainda mais avassaladores no aspecto da oferta, permanência e compreensão política do seu impacto social (FREIRE, 2016). 
O IFRN tem como princípio a defesa dos direitos humanos e a inclusão social. Assim em 2017, de forma ousada e corajosa acolhe alunos privados de liberdade. É essa experiência que vamos contar a seguir.

\section{EXPERIMENTAÇÃO EM EAD PARA PRIVADOS DE LIBERDADE NO INSTITUTO FEDERAL DE EDUCAÇÃO CIÊNCIA E TECNOLOGIA DO RIO GRANDE DO NORTE (IFRN)}

No segundo semestre de 2017, o Campus EAD do Instituto Federal de Educação Ciência e Tecnologia do Rio Grande do Norte teve em seu processo seletivo discente um grupo de 10 alunos advindos do Sistema Prisional Federal. Estes candidatos não foram aprovados por meio de nenhuma política afirmativa de inclusão, mas disputaram em ampla concorrência por estarem aptos ao ingresso na Instituição. Após a superação dos trâmites burocráticos da matrícula, ocorrido através de procurador autorizado judicialmente, efetivamos a entrada destes alunos e iniciamos o semestre ajustando a modalidade a distância às características específicas do universo prisional.

Ao fim daquele semestre, constatamos a efetividade do nosso trabalho através do elevado rendimento de maior parte dos alunos. A partir de então esse processo vem sendo construído. Relatar essa experiência bem como as dificuldades e caminhos possíveis para efetivação do ensinar e aprender em meio a grades é o objetivo deste trabalho. "Para uma pessoa que se encontra privada de liberdade, entende-se que a EaD possa cumprir um papel importante em seu processo educativo (MELGARÉ, 2010, p. 91)"

No Campus EaD do IFRN temos duas graduações: Licenciatura em Espanhol e Tecnólogo em Gestão Ambiental, que são oferecidos via Programa Universidade Aberta do Brasil - UAB.

As pessoas privadas de liberdade e jovens em cumprimento de medida socioeducativa realizam uma prova do ENEM específica: o ENEM PPL (pessoas privadas de liberdade) http://portal.inep.gov.br/web/guest/enem-pll . O que difere do Enem tradicional é apenas a data. Os candidatos que se submetem ao ENEM PPL têm a nota final lançada no banco de dados dos alunos e podem participar do processo seletivo em qualquer instituição do Brasil. No caso dos alunos do Presídio Federal de Mossoró, eles foram aprovados no Campus Mossoró em Gestão Ambiental presencial e em seguida foram transferidos para o Campus EaD.

A experiência é inédita no IFRN; ainda estamos construindo o caminho para um 
atendimento tão específico. Apresentar como o processo de educação prisional está sendo desenvolvido, bem como refletir acerca dessa experiência, contribui para tomarmos decisões sobre quais caminhos seguir. Assim, a pesquisa tem um caráter investigativo/exploratório, mas também intenciona contribuir, a partir da historicização, para a visualização de um quadro que nos apresente um caminho possível para inclusão de jovens e adultos apenados no processo educativo. A "Cela de aula" como nos diz Leme (2007) é um lugar ainda pouco investigado, assim é um lugar com muitas perguntas que aguardam respostas.

As maiores dificuldades enfrentadas na implementação da educação no presídio federal, são as severas restrições de segurança que impossibilitam o acesso de materiais didáticos diversos e equipamentos para aulas experimentais. No âmbito do IFRN, as maiores barreiras são simbólicas. O estigma da prisão enquanto espaço de punição e sofrimento às vezes impede a sociedade de perceber que a pessoa privada de liberdade é um sujeito de direitos e que a Lei impõe a oferta de educação para todos: livres, privados de liberdade, deficientes, hospitalizados, institucionalizados em comunidades

Isto posto, nenhuma instituição educacional pode se ausentar dessa reflexão. Deve puxar para si a responsabilidade para que com outros possamos construir um caminho onde o direito à dignidade possa ser acessado. Onofre 2011, nos diz que os educadores comprometidos com a inclusão social não podem se ausentar da militância pela "elaboração e implementação de políticas públicas voltadas para a educação escolar nos espaços de privação de liberdade, como garantia de possibilidade de resgate de vida digna ao cidadão aprisionado Onofre (2011, p. 268). Onofre (2011, p 275) destaca ainda a Educação Prisional como algo difícil de ser concretizado, mas evidencia que esse lugar é uma vereda para que o apenado possa ser reinserido na sociedade.

O trabalho ainda se encontra em uma fase inicial, de construção de um projeto pedagógico que contempla a educação prisional. Os profissionais envolvidos no processo têm encontrados dificuldades, mas entendemos que o atendimento pela EaD é o caminho. Os pontos que temos privilegiado são:

- Realizar o planejamento, organização e operacionalização do curso, horários, disciplinas, turma e professores para cada período letivo;

- Realizar o acompanhamento pedagógico dos estudantes no processo ensino/aprendizagem no que concerne à avaliação de rendimentos, avaliação do desempenho docente e avaliação do curso; 
- Colaborar na criação, adaptação e distribuição dos materiais didáticos necessários para a realização do curso;

- Coordenar reuniões junto aos professores, alunos e equipe pedagógica da PFMOS;

- Planejar e coordenar as aulas presenciais junto aos professores e PFMOS;

- Incentivar o desenvolvimento de pesquisas e projetos de acordo com o contexto do grupo de alunos;

- Acompanhar, registrar e divulgar o desempenho acadêmico dos estudantes;

- Participar de reuniões, aulas inaugurais e eventos que necessitem a presença do professor;

- Elaborar relatório semestral de desempenho de alunos conforme demandas da Direção Acadêmica do IFRN ou PFMOS.

No âmbito do ensino em EaD estamos dialogando para construção do moodle offline para substituir o moodle, pois, pela situação dos alunos privados de liberdade, estes não podem acessar a internet. O material de uso do aluno tem um processo de impressão diferenciado para atender às severas normas de segurança do presídio. As aulas presenciais acontecem sempre acompanhadas da pedagoga da instituição em um ambiente preparado para isso.

\section{CONSIDERAÇÕES FINAIS}

O Brasil das dívidas sociais com negros, pobres, nordestinos e também com apenados, que em muitas vezes foram excluídos antes de cometerem qualquer delito, tem um dos sistemas penitenciários mais cruéis, (FREI BETO apud KOTSCHO, 2003), "ele destrói a subjetividade do homem, no sentido de não the oferecer nenhuma possibilidade de racionalização da situação em que se encontra. (FREI BETO apud KOTSCHO, 2003, p. 41).

O IFRN na sua experimentação em EAD para privados de liberdade tem iniciado um processo que poderá apontar um caminho possível para a garantia do direito humano à educação para privados de liberdade. Entendemos que a experiência tem um importante papel ao apresentar a ação que começou a ser desenvolvida no período letivo de 2017.2 na Instituição, bem como, contribuir para pesquisas que têm como facetas a EAD e a Educação Prisional. 
O Processo ainda em uma fase inicial já nos aponta algumas veredas: os privados de liberdade têm direito a educação e a EaD é um caminho possível para acessar esse direito.

\section{REFERÊNCIAS BIBLIOGRÁFICAS}

BOIAGO, Daiane Leticia. Políticas públicas internacionais e nacionais para a educação em estabelecimentos penais a partir de 1990: regulação social no contexto da crise estrutural do capital. Dissertação de Mestrado. UNIVERSIDADE ESTADUAL DE MARINGÁ. 2013.

FREIRE, FRANCISCA DAISE GALVÃO. Processos educacionais no cárcere: um estudo sobre as representações sociais de jovens e adultos nas prisões. UFRN. 2016.

www.infopen.gov.br

KOTSCHO, Roberto. Paulo Freire, Frei Betto: Essa escola chamada vida. 14 ed. São Paulo: Ática, 2003.

LEME, J.A.G. A Cela de Aula: Tirando a pena com letras. Uma reflexão sobre o sentido da educação escolar nos presídios. In: . Educação escolar entre as grades. São Carlos: EdUFS Car, 2007

MELGARÉ, Plínio. Dignidade da Pessoa Humana. Malheiros, São Paulo, 2010.

ONOFRE, Elenice Maria Cammarosano. O papel da escola na prisão: saberes e experiências de alunos e professores. Childhood \& philosophy, Rio de Janeiro, v. 7, n.14, jul.-dez 2011, p. 271-297.

ONOFRE, Elenice Maria Cammarosano; LOURENÇO, Arlindo da Silva (Org.). -- 0 Espaço da prisão e suas práticas educativas: enfoques e perspectivas contemporâneas. São Carlos : EdUFSCar, 2011.

RUSCHE, R.J. (Org) Educação de Adultos Presos: Uma proposta metodológica. São Paulo

SANTOS. Boaventura. Para uma sociologia das ausências e uma sociologia das emergências. In: SOUSA SANTOS, Boaventura de (Org.). 
